\title{
Structural damage detection based on improved frequency change ratio
}

\author{
Jian WANG*, Huan JIN, Xiao MA, Bin ZHAO, Zhi YANG, Yaduo LIU, Yi WANG, and \\ Xian WANG \\ China Electric Power Research Institute, Beijing, China
}

\begin{abstract}
Frequency Change Ratio (FCR) based damage detection methodology for structural health monitoring (SHM) is analyzed in detail. The effectiveness of damage localization using FCR for some slight damage cases and worse ones are studied on an asymmetric planar truss numerically. Disadvantages of damage detection using FCR in practical application are found and the reasons for the cases are discussed. To conquer the disadvantages of FCR, an Improved Frequency Change Ratio (IFCR) based damage detection method which takes the changes of mode shapes into account is proposed. Verification is done in some damage cases and the results reveal that IFCR can identify the damage more efficiently. Noisy cases are considered to assess the robustness of IFCR and results indicate that the proposed method can work well when the noise is not severe.
\end{abstract}

\section{Introduction}

Structures may deteriorate and suffer from accumulated damage under the external loads during their service life. When damages occur, the performance of the structure will degrade. It is of great significance to identify the damaged parts of the structure in a timely manner so that we can diminish the probability of accident, enhance the stability and prolong the service life.

Vibration based structural damage detection become an area of intense investigation and gain a lot of research improvement around these decades[1]. Structural damage will induces some changes in the modal parameters of the structure[2], such as the natural frequencies, mode shapes, damping ratios etc. Salawu[3] reviewed the methodologies using natural frequencies as diagnostic parameters for structural damage detection.

In 1968, Fox and Kapoor[4] derived the rates of change of eigenvalues and eigenvectors which traced back to the investigations of Lord Rayleigh. The derivation indicates that the ratio of frequency changes of two different modes is merely a function of damage location, which could be used for damage detection[5].

In this paper, the Frequency Change Ratio (FCR) based damage detection method and its application on an asymmetric planar truss is described in detail and the defects of FCR and

*Corresponding author: 347905482@qq.com 
the possible reasons are discussed. And based on this, some improvements are proposed to form an Improved Frequency Change Ratio(IFCR) damage detection method. The planar truss is applied to investigate the effects of the proposed IFCR method numerically.

\section{Frequency change ratio based damage detection method and Its defects}

\subsection{Frequency change ratio method}

Modal characteristics of a structure, regarding the $i$ th order, are described by the eigenvalue equation as

$$
\left(\boldsymbol{K}-\lambda_{i} \boldsymbol{M}\right) \phi_{i}=0
$$

where $\boldsymbol{K}(n \times n)$ and $\boldsymbol{M}(n \times n)$ are stiffness and mass matrices of the $n$-DOFs structure respectively; $\lambda_{i}=\left(2 \pi f_{i}\right)^{2}$ is the $i$ th eigenvalue and $f_{i}$ is the $i$ th natural frequency. $\phi_{i}$ is the $i$ th mode shape of the structure. When the structure suffers from some damage, and the change of stiffness $\boldsymbol{K}$, eigenvalue $\lambda_{i}$ and mode shape $\phi_{i}$ is $\Delta \boldsymbol{K}, \Delta \lambda_{i}$ and $\Delta \phi_{i}$ respectively, $\Delta \lambda_{i}$ can be expressed as

$$
\Delta \lambda_{i}=\frac{\phi_{i}^{T} \Delta \boldsymbol{K} \phi_{i}}{\phi_{i}^{T} \boldsymbol{M} \phi_{i}}
$$

Supposing only the $d$ th member has a stiffness reduction with $\Delta \boldsymbol{K}_{d}$ and it could be expressed as $\Delta \boldsymbol{K}=\Delta \boldsymbol{K}_{d}=\alpha_{d} \boldsymbol{K}_{d}$, where damage factor $\alpha_{d}$ means the reduction coefficient of the $d$ th member and the damage severity can be expressed as $1-\alpha_{d}$. In addition, change of the eigenvalue can be written as $\Delta \lambda_{i}=\left(\omega_{i}+\Delta \omega_{i}\right)^{2}-\omega_{i}^{2}=2 \omega_{i} \Delta \omega_{i}=8 \pi^{2} f_{i} \Delta f_{i}$.

Similarly, for the $j$ th mode, the equation can be written easily achieved by replacing the $i$ into $j$ in Eq. (2). Define the frequency change ratio of the $i$ th to $j$ th mode frequencies as

$$
F C R_{i j}=\frac{\Delta f_{i}}{\Delta f_{j}}=\frac{\left(\frac{\phi_{i}^{T} \boldsymbol{K}_{d} \phi_{i}}{\phi_{i}^{T} \boldsymbol{M} \phi_{i}}\right) / f_{i}}{\left(\frac{\phi_{j}^{T} \boldsymbol{K}_{d} \phi_{j}}{\phi_{j}^{T} \boldsymbol{M} \phi_{j}}\right) / f_{j}}
$$

As shown in Eq. (3), when there is a single damage occurs on the structure, $F C R_{i j}$ is independent of the damage severity and only related to the damage position. Hence, damage location can be realized through identifying the ratio of natural frequency changes.

Damages may change the natural frequencies of the structure. A judgment index $E_{r}$ is established for the judgement of damage location, which is expressed as

$$
E_{r}=\frac{1}{Q} \sum_{i=1}^{Q}\left[\frac{\Delta f_{i}}{\Delta f_{j}}-\left(\frac{\Delta f_{i}}{\Delta f_{j}}\right)^{*}\right]^{2}
$$

in which $\Delta f_{i} / \Delta f_{j}$ means the frequency change ratio calculated from numerical calculation or experimental results. While $\left(\Delta f_{i} / \Delta f_{j}\right)^{*}$ is the original state, $Q$ is the number of modes participated in the calculation.

\subsection{Damage detection of a planar truss}

\subsubsection{Planar truss model}


A two-dimensional planar truss as shown in Fig. 1 is used to investigate the capability of the FCR damage detection method. The Young's modulus $E$ of the truss elements is $2.0 \times 10^{8} \mathrm{~Pa}$ and the density $\rho$ is $7850 \mathrm{~kg} / \mathrm{m}^{3}$. All bars of the truss have uniform cross sections $A$ $=7.854 \times 10^{-5} \mathrm{~m}^{2}$. The total length of the truss is $6 \mathrm{~m}$ and the length of each horizontal bar is $2 \mathrm{~m}$ while the length of each inclined ones is $\sqrt{2} \mathrm{~m}$.

Fig. 1. Planar truss.

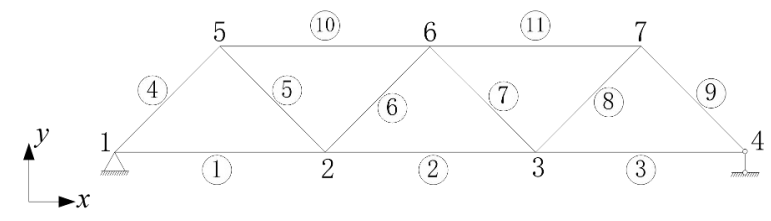

\subsubsection{Damage detection and some problems in practical application}

a) Slight damage cases

When the bar is suffered from slight damage such as the Young's modulus of the $1^{\text {st }}$ member reduces by $5 \%$, the identified $E_{r}$ distribution for damage location is shown as Fig.2.

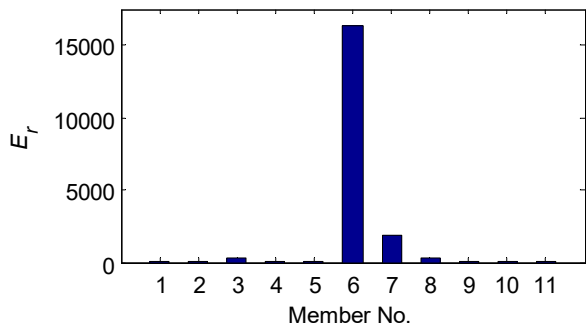

Fig. 2. Er distribution for damage location ( $1^{\text {st }}$ member $5 \%$ damage).

Fig. 2 reveals the $E_{r}$ distribution of each truss member. According to the Eq. (10), the damaged member may have the smallest $E_{r}$ value and we can judge the damage one through comparison of the $E_{r}$ values numerically. But from Fig.2 we can see that some big number such as the $6^{\text {th }}$ and $7^{\text {th }}$ members' $E_{r}$ values lead to bad influences for displaying the targeted smallest values. Therefore, the values calculated in Fig. 2 needs some filtering process. The modified $E_{r}$ distribution for damage location is shown in Fig.3.

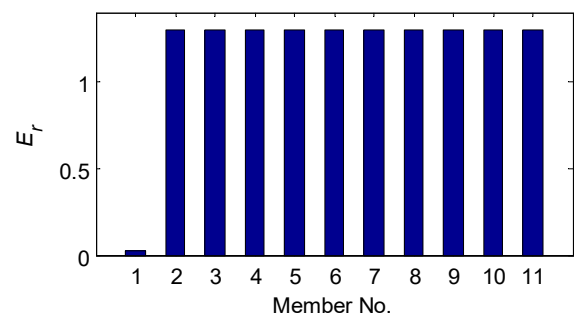

Fig. 3. Modified Er distribution for damage location ( $\left(1^{\text {st }}\right.$ member $5 \%$ damage $)$.

From Fig. 3 we can see that the first member is the damaged bar visibly after filtering process. Therefore, the filtering procedures are adopted in the following papers for damage identification.

For the supposed damage case, five natural frequencies before and after damage are listed in Tab.1. 
Table 1. Frequencies before and after damage.

\begin{tabular}{|l|l|l|l|}
\hline Mode order & $\begin{array}{l}\text { Frequencies before } \\
\text { damage }(F B D)\end{array}$ & $\begin{array}{l}\text { Frequencies after } \\
\text { damage }(F A D)\end{array}$ & $\begin{array}{l}\text { Frequency shift } \\
\text { ratio }(F S R)\end{array}$ \\
\hline 1 & $2.2438 \mathrm{~Hz}$ & $2.2353 \mathrm{~Hz}$ & $-0.38 \%$ \\
\hline 2 & $4.6501 \mathrm{~Hz}$ & $4.5850 \mathrm{~Hz}$ & $-1.40 \%$ \\
\hline 3 & $8.1365 \mathrm{~Hz}$ & $8.1332 \mathrm{~Hz}$ & $-0.04 \%$ \\
\hline 4 & $13.2800 \mathrm{~Hz}$ & $13.2354 \mathrm{~Hz}$ & $-0.34 \%$ \\
\hline 5 & $15.4398 \mathrm{~Hz}$ & $15.4397 \mathrm{~Hz}$ & $-0.00 \%$ \\
\hline
\end{tabular}

where the frequency shift ratio $F S R=(F A D-F B D) / F B D \times 100 \%$. FSR values in Tab.1 show that the frequencies change a little for the damage case. According to the suggestions[3], damage detection could be done with confidence if natural frequencies change about $5 \%$ or more. Hence, FCR method is not suitable for slight damage situations practically.

b) Some worse damage cases

The $1^{\text {st }}$ and $8^{\text {th }}$ members are chosen for damage simulation and several damage severity cases are list in Tab.2. Frequency shift ratios(FSRs) of each mode order are calculated for comparison too. The bolded numbers in Tab.2 are the numbers which are more than or close to $5 \%$. According to Tab.2 different bars with the same damage severity may lead to different frequency change properties. Damage cases which do not have bolded numbers may be infeasible for FCR method. For the damage case of the $8^{\text {th }}$ member suffers from $20 \%$ damage could not be identified practically. For completeness, all the damage cases in Tab. 2 are diagnosed as shown in Fig.4.

Table 2. Frequency shift ratio of damage cases.

\begin{tabular}{|c|c|c|c|c|c|c|}
\hline \multirow{2}{*}{$\begin{array}{c}\text { Damaged } \\
\text { member No. }\end{array}$} & Damage & \multicolumn{5}{|c|}{ Frequency shift ratios(FSRs) } \\
\cline { 2 - 7 } & severity & $1^{\text {st }}$ order & $2^{\text {nd }}$ order & $3^{\text {rd }}$ order & $4^{\text {th }}$ order & $5^{\text {th }}$ order \\
\hline \multirow{4}{*}{1} & $20 \%$ & $-1.81 \%$ & $\mathbf{- 5 . 9 9 \%}$ & $-0.16 \%$ & $-1.38 \%$ & $-0.00 \%$ \\
\cline { 2 - 7 } & $40 \%$ & $\mathbf{- 4 . 9 1 \%}$ & $\mathbf{- 1 3 . 1 4 \%}$ & $-0.33 \%$ & $-2.85 \%$ & $-0.00 \%$ \\
\cline { 2 - 7 } & $60 \%$ & $-\mathbf{1 1 . 1 0 \%}$ & $\mathbf{- 2 1 . 5 3 \%}$ & $-0.51 \%$ & $-4.40 \%$ & $-0.00 \%$ \\
\cline { 2 - 7 } & $80 \%$ & $\mathbf{- 2 6 . 5 0 \%}$ & $\mathbf{- 3 0 . 5 1 \%}$ & $-0.69 \%$ & $\mathbf{- 6 . 0 4 \%}$ & $-0.01 \%$ \\
\hline \multirow{4}{*}{8} & $20 \%$ & $-0.53 \%$ & $-0.05 \%$ & $-0.00 \%$ & $-0.13 \%$ & $-3.08 \%$ \\
\cline { 2 - 7 } & $40 \%$ & $-1.41 \%$ & $-0.14 \%$ & $-0.00 \%$ & $-0.62 \%$ & $\mathbf{- 8 . 2 1 \%}$ \\
\cline { 2 - 7 } & $60 \%$ & $-3.11 \%$ & $-0.31 \%$ & $-0.01 \%$ & $\mathbf{- 6 . 6 4 \%}$ & $\mathbf{- 1 2 . 9 2 \%}$ \\
\cline { 2 - 7 } & $80 \%$ & $-\mathbf{7 . 8 8 \%}$ & $-0.79 \%$ & $-0.05 \%$ & $\mathbf{- 2 5 . 8 7 \%}$ & $\mathbf{- 1 3 . 5 0 \%}$ \\
\hline
\end{tabular}

Comparing Fig.3 with Fig.4, the damage recognition capability of worse damage cases is not as good as the slight damage case. From Fig.4(b) we can see that the $E_{r}$ value of the $2^{\text {nd }}$ member (which is 7.26) is close to the value of $1^{\text {st }}$ member (which is 2.04), and this may decrease the separability of the judgments. For the case shown in Fig.4(c), the $E_{r}$ value of the $1^{\text {st }}$ member, $2^{\text {nd }}$ member and $10^{\text {th }}$ member are close to each other, then it will produce more difficulties for the damage identification. In Fig.4(d) the smallest $E_{r}$ value is located on the $2^{\text {nd }}$ member(which is 6.11) and it would be misjudged as the damaged one. Same mistakes would be done when the $8^{\text {th }}$ member suffers from severe damage as shown in Fig.4(g) and Fig.4(h). Tab.3 shows the concrete relationship between damage severity and MSSR is complex, and generally, there is an approximate trend that the mode shapes will change more as the damage severity increases. Additionally, some mode shape shift ratios are huge under certain damage cases. 


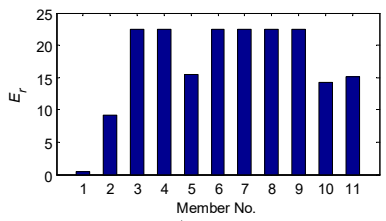

(a) The $1^{\text {st }}$ member, $20 \%$ damage

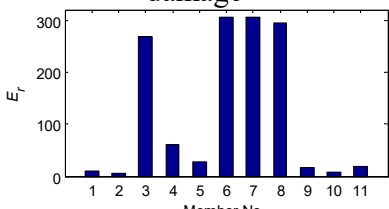

(d) The $1^{\text {st }}$ member, $80 \%$ damage

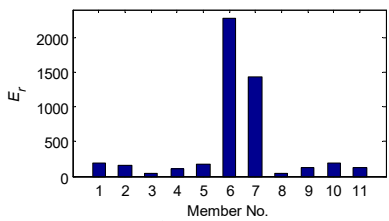

(g) The $8^{\text {th }}$ member, $60 \%$ damage

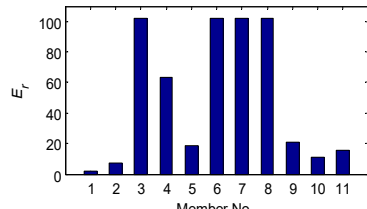

(b) The $1^{\text {st }}$ member, $40 \%$ damage

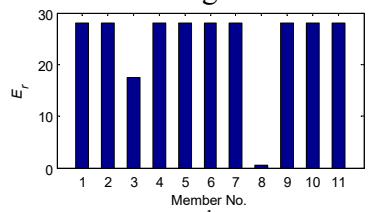

(e) The $8^{\text {th }}$ member, $20 \%$ damage

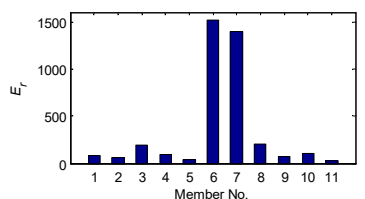

(h) The $8^{\text {th }}$ member, $80 \%$ damage

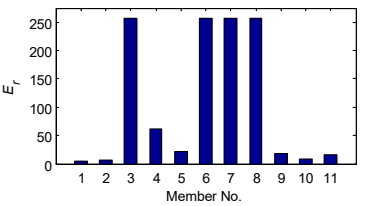

(c) The $1^{\text {st }}$ member, $60 \%$ damage

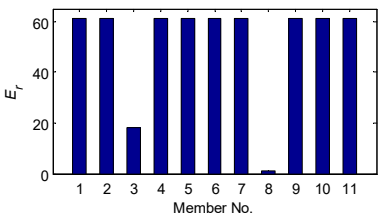

(f) The $8^{\text {th }}$ member, $40 \%$ damage

Fig. 4. Damage localization.

The more the damage severity increases, the more the frequencies change. This phenomenon means that more serious damage is beneficial for FCR damage detection. But the mode shapes will shift more at the same time and it will inhibit the validity of the damage detection method.

\section{Improved frequency change ratio based damage detection method}

\subsection{Improvement method for FCR}

In the light of analysis in section 2.2.2, the mode shape shift could not be neglected. We can get

$$
\left(\boldsymbol{K}-\lambda_{i} \boldsymbol{M}\right) \phi_{i}+\left(\Delta \boldsymbol{K}-\Delta \lambda_{i} \boldsymbol{M}\right)\left(\phi_{i}+\Delta \phi_{i}\right)+\left(\boldsymbol{K}-\lambda_{i} \boldsymbol{M}\right) \Delta \phi_{i}=0
$$

considering Eq. (1) and noting that $\phi_{i}^{T}\left(\boldsymbol{K}-\lambda_{i} \boldsymbol{M}\right)=\boldsymbol{0}^{T}$, Eq. (5) can be simplified as

$$
\Delta \lambda_{i}=\frac{\phi_{i}^{T} \Delta \boldsymbol{K} \phi_{i}^{D}}{\phi_{i}^{T} \boldsymbol{M} \phi_{i}^{D}}
$$

where $\phi_{i}^{D}$ is the $i$ th mode shape of the damaged structure, $\phi_{i}^{D}=\phi_{i}+\Delta \phi_{i}$. Neglect the change of mode shape $\Delta \phi_{i}$, then Eq. (6) will become the Eq. (2). Different from the FCR method, the high order terms $\varphi_{i}^{T}\left(\Delta \boldsymbol{K}-\Delta \lambda_{i} \boldsymbol{M}\right) \Delta \varphi_{i}$ are not neglected as usual, and actually, Eq.

(6) is exactly the equation of the parameters without any errors. Conveniently, we call this method the Improved Frequency Change Ratio (IFCR) method.

\subsection{Damage localization using IFCR}


Utilizing the IFCR, damage detection of the $1^{\text {st }}$ member $5 \%$ damage is shown as shown in Fig.5.

Table 3. Mode shape shift ratios.

\begin{tabular}{|c|c|c|c|c|c|c|}
\hline \multirow{2}{*}{$\begin{array}{c}\text { Damaged } \\
\text { member No. }\end{array}$} & Damage & \multicolumn{5}{|c|}{ Mode shape shift ratios(MSSRs) } \\
\cline { 3 - 7 } & severity & $1^{\text {st }}$ order & $2^{\text {nd }}$ order & $3^{\text {rd }}$ order & $4^{\text {th }}$ order & $5^{\text {th }}$ order \\
\hline \multirow{3}{*}{1} & $20 \%$ & $6.85 \%$ & $2.44 \%$ & $7.56 \%$ & $1.54 \%$ & $0.91 \%$ \\
\cline { 2 - 7 } & $40 \%$ & $17.22 \%$ & $5.14 \%$ & $16.16 \%$ & $3.44 \%$ & $2.15 \%$ \\
\cline { 2 - 7 } & $60 \%$ & $33.22 \%$ & $7.75 \%$ & $26.16 \%$ & $5.68 \%$ & $3.88 \%$ \\
\cline { 2 - 7 } & $80 \%$ & $53.04 \%$ & $7.51 \%$ & $38.22 \%$ & $8.18 \%$ & $6.43 \%$ \\
\hline \multirow{4}{*}{8} & $20 \%$ & $-0.42 \%$ & $-0.26 \%$ & $-0.30 \%$ & $8.89 \%$ & $7.04 \%$ \\
\cline { 2 - 7 } & $40 \%$ & $-1.10 \%$ & $-0.69 \%$ & $-0.84 \%$ & $-238.75 \%$ & $26.36 \%$ \\
\cline { 2 - 7 } & $60 \%$ & $-2.42 \%$ & $1.57 \%$ & $-2.15 \%$ & $-284.52 \%$ & $60.93 \%$ \\
\cline { 2 - 7 } & $80 \%$ & $-6.01 \%$ & $4.19 \%$ & $-9.42 \%$ & $-217.49 \%$ & $49.62 \%$ \\
\hline
\end{tabular}

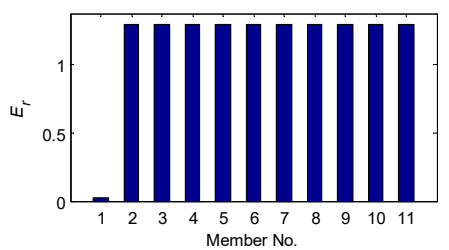

Fig. 5. Damage localization of damage case of $1^{\text {st }}$ member $5 \%$ damage.

When the damage is slight, the influence of mode shape caused by damage will be small, the IFCR can also identify the damage location successfully as shown in Fig.5.

For some worse damage cases, three damage cases are chosen to verify the localization ability of the proposed IFCR damage detection method. Damage case I represents the $1^{\text {st }}$ member occurs $30 \%$ damage severity, damage case II represents the $1^{\text {st }}$ member suffers from $70 \%$ damage severity, and the damage case III means the $8^{\text {th }}$ member has $70 \%$ damage severity. Using the proposed IFCR method, and applying the filtering process, $E_{r}$ distributions for damage localization are shown in Fig.6. The damaged members can be distinguished apparently in Fig.6 and hence IFCR is a better damage detection method.

\subsection{Noise affections}

As we all known, frequencies can be measured with a high precision while the mode shapes may be influenced more severely under the present experimental techniques. Some random noises are added to the calculated frequencies and mode shapes. The contaminated frequency with noise can be gained using the following equation:

$$
f^{\prime}=f(1+\eta \times \operatorname{rand}[-1,1])
$$

where $f$ is the calculated frequency, $f^{\prime}$ is the contaminated frequency with noise, $\eta$ denotes the noise level(e.g. 0.05 relates to a 5\% noise level) and rand is a random number in the range[-1,1]. Like the frequency, mode shape with noise can also be expressed like Eq. (9).

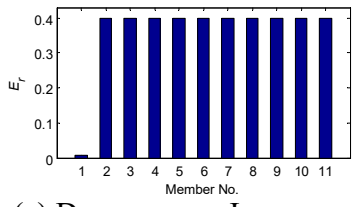

(a) Damage case I

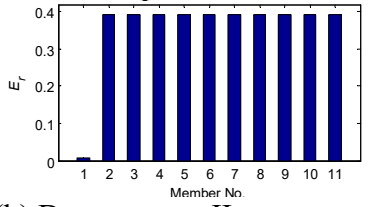

(b) Damage case II

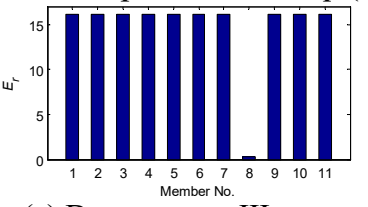

(c) Damage case III

Fig. 6. Damage localization by IFCR.

According to this, a serious of noises listed in Tab.5 is added in the natural frequencies and mode shapes for damage identification. 
Table 5. Noise cases.

\begin{tabular}{|c|c|c|}
\hline Assembled noise case No. & Noise level for frequencies & Noise level for mode shapes \\
\hline Noise case I & $5 \%$ & $10 \%$ \\
\hline Noise case II & $10 \%$ & $15 \%$ \\
\hline Noise case III & $15 \%$ & $20 \%$ \\
\hline
\end{tabular}

In order to reveal the typical influence of the noises, damage case I is selected to be mixed with the noises. The IFCR method is adopted to identify the damaged location and the results are shown in Fig.7.

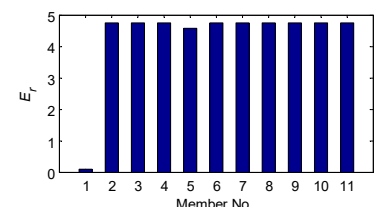

(a) Noise case I

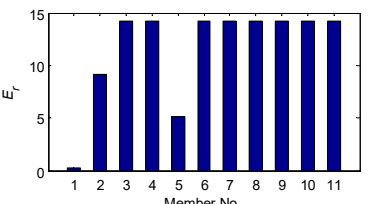

(b) Noise case II

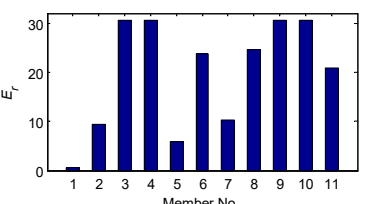

(c) Noise case III

Fig. 7. Damage localization for damage case I with noises.

As shown in Fig.7, the noises may do harmful impact to the damage identification to some severity. IFCR method can identify the damage location clearly even though the frequencies and mode shapes are suffered from $5 \%$ and $10 \%$ noises respectively. The recognition effect of damage case I under noise case I reflects that IFCR has a strong antinoisy ability. When the noises increase, the identification ability will decline such as the noise case III, misjudgment may be done in this situation.

\section{Conclusions}

Frequency change ratio based damage detection method is discussed in detail in this paper. The identification for a planar truss shows that the FCR method may have some disadvantages for recognizing some slight damage cases and the worse damage cases in practical situations. Accordingly, an improved frequency change ratio based damage detection method IFCR is proposed. Damage localization effects in noise-free and noise cases are studied and the results show that the proposed IFCR method can identify the damaged member accurately when the noise is not very severe.

\section{References}

1. Fan, W., \& Qiao, P. (2010). "Vibration-based damage identification methods: a review and comparative study", Structural Health Monitoring, Vol. 9, No. 3, pp. 83-111.

2. Farrar, C. R., and Worden, K. (2007). "An introduction to structural health monitoring", Philosophical Transactions of the Royal Society A Mathematical Physical \& Engineering Sciences, Vol. 365, No. 1851, pp. 1-17.

3. Salawu, O. S. (1997). "Detection of structural damage through changes in frequency: a review”, Engineering structures, Vol. 19, No. 9, pp. 718-723.

4. Fox, R. L., \& Kapoor, M. P. (1969). Rates of change of eigenvalues and eigenvectors. Aiaa Journal, 6(12), 2426-2429.

5. Cawley, P., \& Adams, R. D. (1979). "The location of defects in structures from measurements of natural frequencies", The Journal of Strain Analysis for Engineering Design, Vol. 14, No. 2, pp. 49-57. 